\title{
Editorial
}

\section{An embarrassment of riches}

Elaine Hall

Northumbria University, UK

Elaine.Hall@northumbria.ac.uk

This edition is so full of good things and arrives alongside the fantastic bounty of the joint IJCLE-CLEO-ENCLE conference (follow this link to find out the details of papers and later, to view presentations) that I am going to renege on my promise in the last edition to provide more editorial content.

I will simply urge you to feast on

- Recipes for mapping legal need from Richard Owen

- Sustaining data on the student experience of pro bono from Paul McKeown

- A palate cleansing look at the European Clinical literature from Rachel Dunn

- A seven course banquet of Streetlaw pedagogy from Seán Arthurs, Melinda Cooperman, Jessica Gallagher, Freda Grealy, John Lunney, Rob Marrs and Richard Roe

- Rich reflections from the development of clinic from Stefan Kreiger, Veronika Tomoskova and Maxim Tomoszek

- and just when you thought your appetite was sated, a tempting review of Research Methods in Human Rights: a Handbook by Christopher Morris. 
Next edition will see the return of 'archive dive' in November - unless the flow of clinical scholarship continues at its current rate and we need to have an extra edition in September. Meanwhile, I look forward to meeting those clinicians who are able to come to Newcastle for the conference and encourage those of you who can't be there to follow us on twitter (@ijcle \#IJCLE17). One final piece of exciting news, the 2018 IJCLE conference will take place in Hong Kong in collaboration with the Faculty of Law at the Chinese University of Hong Kong - more details soon! 